\title{
A Comprehensive and Additive System for Child-Focused Assessment and Evaluation in EI/ECSE
}

\author{
Diane Bricker, Jane Squires*, Rebecca Frantz and Huichao Xie
}

Early Intervention Program, University of Oregon, USA

\begin{abstract}
One of the more serious problems facing the field of early intervention/early childhood special education is the disconnect between the community programs that offer screening, eligibility determination, curricular assessment (i.e., programmatic assessment), and progress monitoring services. First, we provide definitions of these service components to ensure clarity. Second, the substantial disconnect found between the screening, eligibility determination, curricular assessment, and progress monitoring components in most communities is discussed. Third, an alternative conceptual framework and its rationale are offered. This framework is designed to ensure that information collected is comprehensive, and that information/data gathered during each component serves as the platform for the next component. An example clarifies the application of the framework.
\end{abstract}

Keywords: Early intervention/early childhood special education, disconnect, assessment, screening, eligibility determination, programming, progress monitoring, systems framework.

\section{INTRODUCTION}

In comparison to our modest beginnings in the 1960 's, when the first community based programs for young children with disabilities originated and the Handicapped Children's Early Education Program (HCEEP) was enacted in 1968, the field of early intervention/early childhood special education (El/ECSE) has come a long way. El/ECSE has evolved into a national network of assessment/evaluation and intervention services for young children with disabilities birth through age five years that is undergirded with federal legislation, and often augmented by state regulations. In addition, every state has higher education programs that prepare, at least in part, personnel to work with young children with disabilities. We have created a modest research base that adds credibility to the services being delivered to children and their families [1-3]. Finally, an array of materials is now available to enhance screening, assessment/evaluation and intervention services as well as personnel preparation efforts.

Despite accomplishments in providing services to young children with disabilities, there remains a number of contemporary challenges. Elsewhere we have discussed the need for the field of El/ECSE to adopt models or frameworks that link the major components of screening, eligibility determination, programmatic assessment, and program evaluation [2]. We have argued for an approach that links or connects these major activities or components to each other in

*Address correspondence to this author at the University of Oregon, $901 \mathrm{E} .18^{\text {th }}$ St Suite 139, Eugene, OR, 97403, USA; Tel: (541) 346-2634;

Fax: (541) 346-2594; E-mail: jsquires@uoregon.edu ways that eliminate unnecessary expenditures and redundancy $[4,5]$. Others have also pointed out the need for El/ECSE to adopt systems approaches [6]; unfortunately, we see little movement in this direction to date.

In particular, this paper focuses on what we think is a serious disconnect between the assessment/ evaluation components that first identify children, establish their eligibility for services, generate intervention goals/objectives and content, and monitor progress toward the acquisition of target goals and objectives. Our major purpose is to offer an alternative conceptual framework that we believe addresses this disconnect between essential El/ECSE components that govern the detection, evaluation and delivery of services for young children at risk and who have disabilities and their families.

It is important to note that we offer a conceptual model that we believe has merit. Our purpose is to stimulate discussion about how to improve assessment and evaluation practices in the field of El/ECSE. Our intent is to encourage discussion to improve and clarify the proposed framework. Subsequent steps will need to address how to collect the necessary data to evaluate the empirical validity of the framework should it pass the scrutiny of theoretical lenses.

The reader should be aware of several important qualifiers associated with the content of this paper. First, the content is focused on the field of El/ECSE, that is for children birth through five years of age with disabilities and at-risk for disabilities. Second, the content only addresses selected assessment and evaluation components. For example, larger issues 
associated with program evaluation are not discussed. Third, assessment and evaluation of family or environmental variables are not considered. Fourth, as noted above, the paper offers only a conceptual framework.

To begin, this paper offers definitions of the major terms used in the proposed framework. Next we discuss the "serious disconnect" between contemporary El/ECSE assessment and evaluation components. Then we offer an alternative conceptual framework -- a comprehensive and additive system -that is designed to address this disconnect between essential El/ECSE components. Finally, we provide an example of the proposed framework.

\section{DEFINITIONS}

After considerable angst, we have chosen the title "A Comprehensive and Additive System for Child Focused Assessment and Evaluation in El/ECSE." To help ensure the reader understand our meaning, we will define the major terms in this title. The proposed model is comprehensive in that it includes all the fundamental assessment and evaluation components associated with El/ECSE, and additive in that it is designed to move child data/information gathered at each stage (i.e., screening, eligibility determination, programmatic assessment, and progress monitoring) forward as the basis for the next component. For example, a child's fine motor performance may raise concerns on a developmental behavioral screening assessment. When an additive process is used, the fine motor concerns would be investigated further when a more comprehensive assessment is administered. If the concerns are corroborated with additional data, then the child's goals, curriculum/intervention, and progress monitoring with a programmatic assessment will target the deficient fine motor skills. Finally, system refers to to combining a number of elements or components into a more complex functioning whole.

In terms of the components of our proposed system, we use the term assessment to refer to the collection of data to establish an entry developmental or performance baseline or status; while the term evaluation refers to some form of comparison in order to determine effects or impact or change over time [4]. Our present focus is on the progress monitoring aspect of evaluation.

To ensure further clarity, we first define the four assessment/evaluation components that we address in our proposed conceptual model: a) screening, b) eligibility determination, c) programmatic assessment, and d) progress monitoring. We offer definitions of these elements because considerable variation exists in how assessment/evaluation terms are defined in the EI/ECSE literature [7, 8].

\section{Screening}

We have defined screening elsewhere as the component in which the process of determining children's developmental-behavioral status is addressed using a brief, easy to complete, standardized test that reliably discriminates between children who should be referred for more in-depth assessment and those who should not be referred [2, 9]. The purpose of screening is to identify developmental concerns. Examples of screening measures include the Denver II [10] and the Parents' Evaluation of Developmental Status (PEDS) [11].

\section{Eligibility Determination}

This component refers to determining if children meet established state-adopted federal guidelines mandated by the Individuals with Disabilities Education Act (IDEA) for receiving free, appropriate El/ECSE services. Eligibility usually involves a standardized, formal assessment in which children are given a range of developmental tasks to perform. Their performance is scored and compared to a normative standard such as same-age peer performance. The purpose of eligibility determination is to establish whether or not children meet federal and state guidelines for special education services. Traditional examples of measures used for determining eligibility include the Bayley Scales of Infant Development III [12] and the Stanford Binet Intelligence Scale [13].

\section{Programmatic Assessment}

We refer to programmatic assessment as the component in which information about a child's current level of performance across a range of essential developmental tasks such as motor, cognitive, language, and adaptive skills is gathered.

The purpose of programmatic assessment is to develop appropriate goals and objectives/outcomes (i.e., developmental teaching targets), and intervention content to address the selected goals and objectives. Outomes or goals/objectives are part of the Individualized Family Service Plan (IFSP) or Individualized Education Program (IEP) under the 
federal Individuals with Disabilities Education Act (IDEA). Programmatic measures are usually curriculum-based, curricular-referenced, or curriculumembedded [31]. In these measures, the criteria for developmental or instructional targets and for on-going progress monitoring are specified. The items on these measures function as both the instructional targets and the items that are evaluated during progress monitoring Examples include the Assessment, Evaluation, and Programming System [4] and the Hawaii Early Learning Profile [14].

\section{Progress Monitoring}

We refer to the final component as progress monitoring -- a facet of the broader category of program evaluation. This component provides comparative data on child performance at weekly, quarterly, and/or annual intervals, and can include formal data collection on discreet skills as well as informal measures such as portfolios and videos. There are many ways and strategies to collect progress monitoring data associated with such factors as the type of goal/objective, and program resources. The purpose of progress monitoring is to provide useful feedback on the effects or impact of intervention efforts as specifically related to target goals/objectives. For example, if a child's goal is to increase the number and type of words used at home and school, progress monitoring data would target assessing the extent to which intervention efforts are, in fact, increasing the child's word production.

We offer the above definitions to ensure that the reader understands the terms we use including the four components we address in the proposed conceptual framework-a framework designed to eliminate the disconnection between these components. Before discussing the proposed framework, the next section addresses, in more detail, what we perceive to be the existing disconnections between assessment/ evaluation activities in many of $\mathrm{El} / \mathrm{ECSE}$ programs throughout the country.

\section{THE DISCONNECT BETWEEN ASSESSMENT/ EVALUATION ACTIVITIES}

Clearly there are El/ECSE programs in some communities that have organized, coordinated efforts that successfully link the components of screening, eligibility determination, programmatic assessment, and progress monitoring. However, our experience and overall sense is that such coordinated efforts are infrequent. We believe that it is a widespread phenomena among many communities that the essential four components of assessment and evaluation are disconnected, unrelated, and/or redundant. Our specific observations of the disconnection between the four assessment and evaluation components are discussed next.

\section{Screening Disconnects}

Our knowledge of most community screening efforts suggests that they are conducted separately from other services and may be performed independently by an array of agencies such as physicians, local Head Start programs, El/ECSE programs, and public health entities [2]. In many communities, screening services may be both redundant (e.g., children and parents were asked to do the same thing or the same questions again and again in different procedures) as well as have gaps (e.g., in rural areas, screening is often nonexistent). Funding for screening services can vary widely and is often associated with the scope of screening undertaken in a community. That is, modest funding results in limited screening services. Few communities have centralized referral systems $[15,16]$.

For children who do not exhibit "typical" development during screening, referral to an agency to determine eligibility for public services should be straightforward and informative; however, our experience suggests this is often not the case. Again, in many communities the connection between screening services and state-approved services for determining eligibility is tentative at best $[17,18]$. In addition, the information acquired during screening is often in a format that is of little use to the referral agency (e.g., does not offer information to assist in determining a place to begin eligibility assessment). Thus, it seems that what was learned during the screening process has little to no specific impact on eligibility determination. Our sense is that for most agencies the child examination for eligibility is begun as a blank slate!

\section{Eligibility Disconnects}

We are aware that eligibility determination varies across communities and between states. However, most states have historically required the use of standardized measures to determine a child's eligibility [19-21] and the criteria for eligibility are specified by state.

Most eligibility determinations are conducted by a group of professionals who represent different 
disciplines (i.e., multi-disciplinary teams). The team determines if the child meets state standards for free, public services and often this group develops an IEP/IFSP for the child [25]. For example, in some regions, especially in medically related settings, a multi-disciplinary team conducts an in depth evaluation in which each team member administers a separate assessment of the child using a standardized or a discipline relevant test, or both. Parents or primary caregivers are frequently asked the same questions as they "visit" each professional with their child. Once the testing is completed, the team convenes to determine if the child meets the state criteria for eligibility to receive IDEA services.

Mirroring medical processes, eligibility assessments are designed to measure how much a child deviates from the norm; that is, deviates from children that are "normally" or typically developing. Measuring deviancy usually requires administration of norm-referenced tests. Administration of these tests requires extensive training, involves significant time investments, and thus is a costly undertaking [23, 24]. As noted, the cost is extremely high per child. Depending upon state definitions and the complexity of a disability, programs may expend more time and money conducting an eligibility assessment than for actual hands-on intervention with young children and families [25].

Additionally, eligibility tests gather decontextualized information, meaning that they measure discreet tasks that separate children by age norms, rather than measure functional skills that children are called upon to use in daily activities [26]. Accuracy, utility, equity, sensitivity, and convergence are often lost in this assessment process, resulting in biased and inaccurate results with assessment outcomes that cannot be easily applied for programmatic (i.e., intervention) purposes [14, 26].

More recently, best practice recommendations associated with eligibility determination have broadened to include approving the use of curriculumbased assessments that yield information of relevance to the development of IEP/IFSPs and intervention content [27-30]. Acceptance of more interventionrelevant measures by state agencies has moved slowly and consequently the information gathered during the eligibility determination process remains largely inapplicable and/or irrelevant to the next component of programmatic assessment. Although information obtained during this component may go forward with the child when referred to an intervention program, the information is frequently of limited use for the teachers, interventionists, and specialists whose task is to select goals and objectives and develop associated intervention content.

\section{Programmatic Assessment Disconnects}

Our observed "disconnect" extends to the next component of programmatic assessment for those children found to be eligible. Most children who qualify for services are referred to an intervention program to be served in home based, center based, or combined setting. In some states/communities, the multidisciplinary team develops the IEP/IFSP but in others, the service personnel in the intervention program develop the IEP/IFSP $[8,31]$. In cases where the multidisciplinary team develops the IEP/IFSP, the content is usually based on the child's performance on a standardized test and/or discipline-related tests and parental input--the amount of which can vary enormously depending on the sensitivity of team members. As noted, often this content is of little value to the receiving program personnel [31] who may feel the need to administer a more relevant assessment in order to better understand the child's developmental status and to derive content for targeting goals and objectives and deriving subsequent intervention content. For service programs that receive a child without an IEP/IFSP, their personnel must administer a relevant (usually an intervention-based) tool) in order to develop an appropriate IEP/IFSP. Often the data/ information passed on to the service program from the multi-disciplinary assessment is of little or no value to this group of professionals-so many teachers and interventionists have told us. For example, diagnostic information often is not translated into concrete actions- such as the child has a metabolic disorder but no guidance is offered as to the potential implications for intervention efforts.

\section{Progress Monitoring Disconnects}

Progress monitoring is the fourth component and offers the strongest linkage with the previous process of programmatic assessment. However, we also see a disconnection between programmatic assessment and progress monitoring. In our view, progress monitoring procedures should examine child progress toward selected goals and objectives. Comparison of target child behaviors over time should inform the child's team about the effectiveness of intervention efforts. As noted earlier, the major purpose of progress monitoring is to determine if the child is making acceptable progress toward his/her developmental targets. 
Our informal review of progress monitoring efforts suggests three serious problems. First, many of the targeted IEP/IFSP goals and objectives are written in non-measurable terms. For example, "the child will improve his language skills" is vague and does not indicate how this will be measured. Second, staff do not collect data reliably both in terms of regularity (e.g., twice a week) or in terms of established inter-rater agreement. Third, the collected comparison data are not transposed into useable outcomes that can be reviewed by team members. Data may be gathered by one or more specialists but not shared with classroom teachers nor used to inform intervention efforts. If this analysis is correct, then again a serious disconnection exists between the components of programmatic assessment and progress monitoring.

Our strong impression, supported by limited data, is that currently in most communities the components of screening, eligibility determination, programmatic assessment, and progress monitoring are basically unrelated. Additionally, the information derived during one component is not used to inform or to build upon the next component. We find this situation to be unacceptable for several reasons.

First, this disconnection between assessment/ evaluation components is wasteful of limited resources. Professionals do not take advantage of previous professionals' information gathering and assessment results. Consequently, time and resources are wasted. Second, children and parents are often subjected to the same activities and communications during each component-again a waste of valuable resources, not to mention to the dismay of parents. Third, fewer children/families can be served or children receive reduced services because of the inefficiency of the separate processes undertaken in each component that do not build successively on previously acquired information/data.

To address these serious problems, we need a system that is both comprehensive and additive. The remainder of this paper describes such a systems approach designed to coordinate the four assessment/ evaluation components by using and building on the data/information acquired at each stage. We begin by describing how such a system might work conceptually. We end by offering a concrete example of how to connect assessment/evaluation components and additively build in order to maximize the effectiveness and efficiency of the proposed system.

\section{PROPOSED CONCEPTUAL FRAMEWORK FOR A COMPREHENSIVE, ADDITIVE SYSTEM}

In order to advance early childhood assessment/ evaluation practice, we propose a system that is comprehensive, and additive. That is, it is composed of identified elements or components that work together to create an operational whole. The system is comprehensive in that it addresses what we believe are the major components of the assessment/evaluative process that should be employed in El/ECSE programs. Finally, it is additive in that information gathered during each assessment/evaluation component informs the next component. That is, at each assessment/evaluation component-screening, eligibility determination, programmatic assessment, and progress monitoring-additional information is

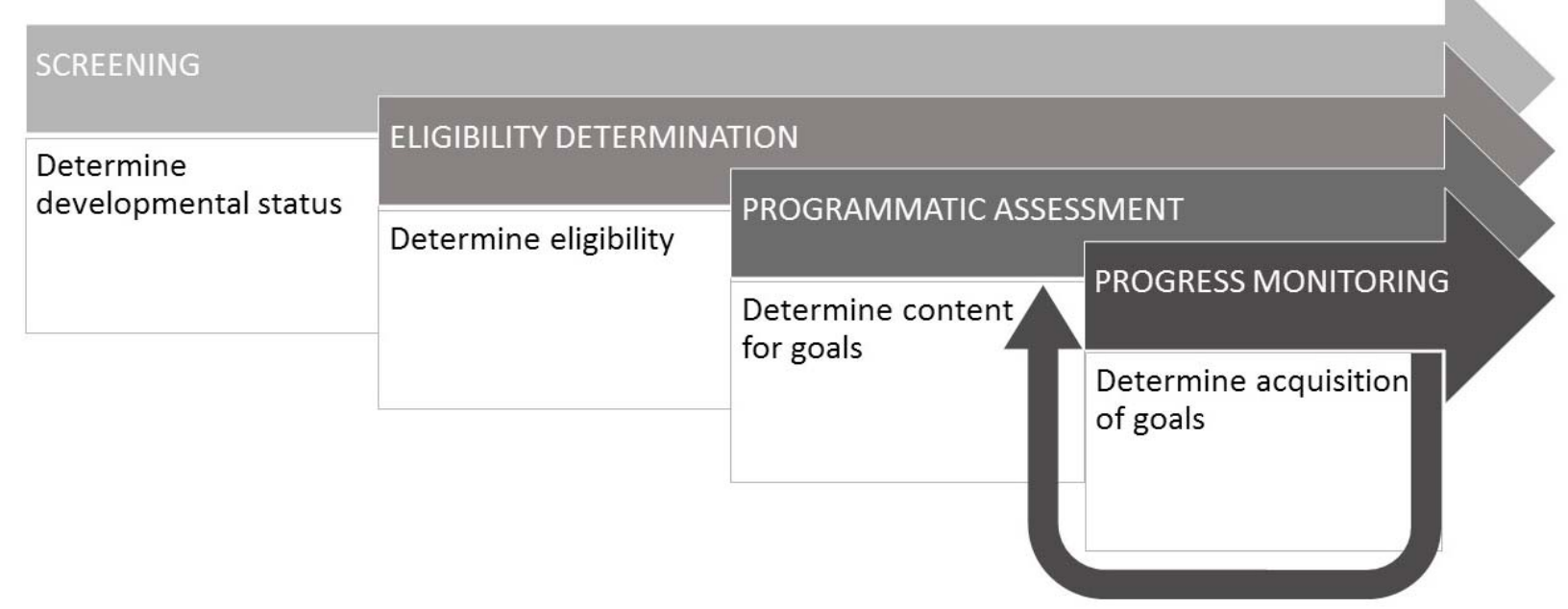

Figure 1: A schematic of the proposed system illustrating four linked components that are comprehensive, as well as progressively additive, in that data from each succeeding component serve as the basis for further information gathering. 
collected that further enhance the database that has already been collected and further describes the child's total repertoire. Also, this information and/or data can, and should, contribute to the eventual design of intervention activities. Finally, this information base should serve as the basis for monitoring child progress. Figure 1 shows how information is collected and added throughout the major components of the assessment/ evaluative process.

For example, during the screening process, Asher, a 3-year-old, was assessed in all developmental domains with potential delays indicated in his gross motor skills. Asher is walking independently with occasional falls, sitting on a tricycle but not pushing the pedals, throwing a large ball, and running a short distance without falling. Asher is not as yet able to walk up or down steps independently or kick a ball. More indepth information is then collected on Asher's gross motor skills during the eligibility determination process, with Asher's parents and a motor specialist observing Asher's skills while having him play various games inside and outdoors. Asher's performance of motor skills is then compared to normative data - what is the age that children run and avoid objects, hop and jump, and walk up stairs? Is Asher significantly delayed in these and related skills? As these skills usually emerge around 2 years of age, a 3-year old such as Asher, who cannot yet perform these gross motor behaviors, may be eligible to receive El/ECSE services in most states, and an IEP or IFSP would be developed in conjunction with Asher's family. Information collected on Asher's gross motor skills can then be augmented by further assessment using a curriculum-based measure that assists in helping the team select goals that will improve the Asher's motoric functioning across environments. Many curriculum- based measures include the developmental equivalents or normative information on goals and objectives. Data can be collected on his ongoing walking skills, including how well he is able to navigate around objects, whether he can climb up the stairs to the play room without assistance, and if he can kick a soccer ball during outdoor play. This progress monitoring will track Asher's performance on these targeted gross motor goals and objectives over time.

Figure 2 presents a second schematic of the comprehensive and additive framework we are proposing. The figure is composed of the four assessment/evaluation components of screening, eligibility determination, programmatic assessment and progress monitoring. These components are shown at the top of the figure and reflect the comprehensive coverage of the framework beginning with screening and culminating in progress monitoring. The arrows connecting each of the components depict the additive feature of the framework in that information or data collected at each component is sent forward to form the basis or beginning point for the next component. The components form a system in that each contributes to the overall purpose of delivering quality services to young children and their families.

In addition, Figure $\mathbf{2}$ shows the purpose or potential outcome associated with each component. That is, the purpose of screening is to determine children's general developmental status. Children's performance status can be compared against norms to determine if they appear to be developing without problems (i.e., OK) or whether further more comprehensive assessment is required (i.e., AT RISK). The purpose of eligibility determination is to ascertain if children meet the criteria for receiving special education services. For children who are determined to be eligible for El/ECSE services, the purpose for programmatic assessment is to provide more detailed information about what children can do and what are the next appropriate

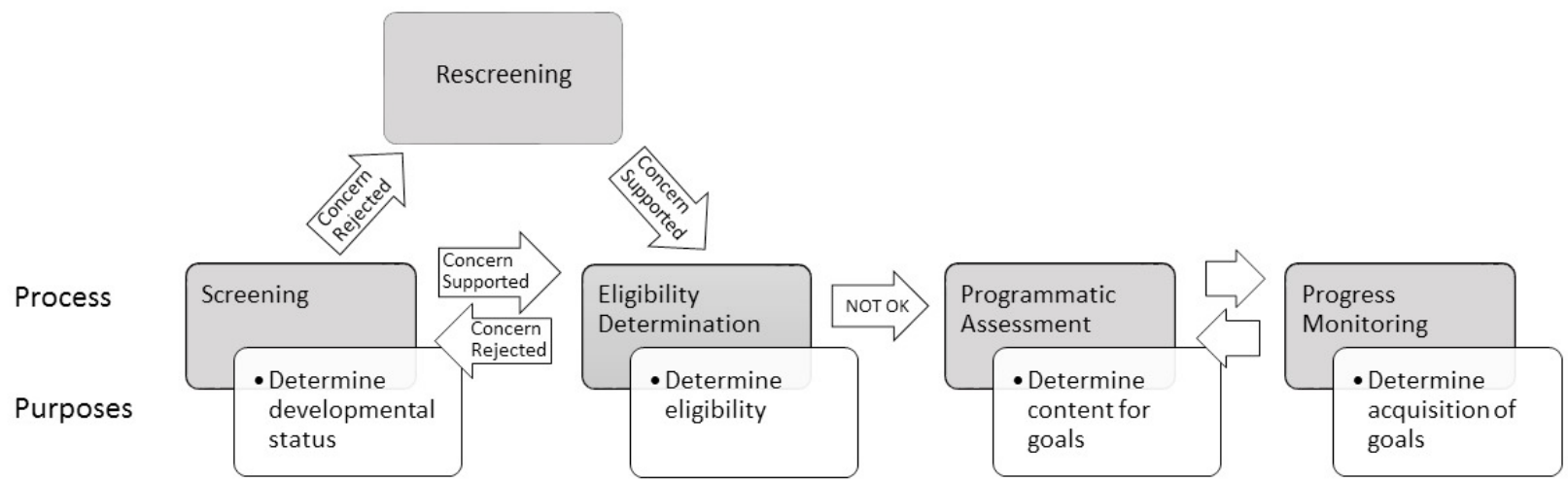

Figure 2: Conceptual framework for a comprehensive, additive assessment/evaluation system for El/ECSE. 
developmental targets and the associated intervention content. Finally the purpose of progress monitoring is to assess over time children's acquisition of targeted goals and objectives.

As noted, the framework is designed to be both comprehensive in that all major assessment/evaluation components are addressed and additive in that information is consistently forwarded to each succeeding component (as shown by the arrows in Figures $\mathbf{1}$ and 2).

\section{APPLICATION OF THE PROPOSED FRAMEWORK}

The following section offers an example of how the proposed comprehensive, additive framework might unfold. A scenario is used to demonstrate each of the four components of screening, eligibility determination, programmatic assessment, and progress monitoring. For each component procedures are described and discussed.

\section{Screening}

\section{Scenario}

Sally, who is 30 -months-old, has recently begun attending Rainbow Center in her community. In initial meetings with center staff, her parents raised some significant concerns about Sally's language and social development in comparison to some of the other children at the childcare center. They also reported that Sally needs significant support at home with daily routines, such as eating with utensils and dressing. The Rainbow Center staff has also noticed delays in Sally's language, social interactions, and adaptive skills.

Sally's parents completed the 30-month Ages \& Stages Questionnaires, Third Edition (ASQ-3) [32] that was sent home, and center staff reviewed the completed measure. Based on parental assessment using the ASQ-3, Table 1 contains the developmental areas of the ASQ-3, Sally's score for each area, area cut-off scores, and Sally's developmental status based on her scores.

Sally's results on the ASQ-3 align with parent and program staff concerns. As noted in Table 1, Sally's scores in the Gross Motor, Fine Motor, and Problem Solving are above the cut-offs in those areas, suggesting she meets age expectations in those domains. However, her scores in the communication and personal social areas suggest she is not performing as typical 30-month olds. Sally's score for the Problem Solving area was 30 , which is above but close to the cut-off score for her age, indicating that her performance was at risk and a referral for further evaluation or follow-up screening was needed. The outcomes from the screening component generate the initial information on Sally's developmental status and provide the basis or platform for conducting further assessment during eligibility determination, the second component. When making the referral, the screening findings should be included - the raw data as well as a summary report prepared by the screening team. This report along with the ASQ-3 performance data should form the basis for beginning the eligibility determination process.

\section{Eligibility Determination}

\section{Scenario}

The staff from Rainbow Center referred Sally's parents to Early Childhood SUPPORTS, the local El/ECSE service provider responsible for conducting eligibility determination evaluations and providing support services consistent with stipulations of the developed IFSP or IEP if children are found eligible. Members on the evaluation team included a school psychologist as the lead evaluator, an early interventionist (EI) and a speech-language pathologist (SLP) as the co-evaluators. They used three sources of information to determine Sally's eligibility for free public education/therapeutic services: a) information from the screening measure, b) information from parents, and c)

Table 1: ASQ-3 Areas, Sally's Scores, Area Cut-Off Scores, and Sally's Developmental Status in these Areas

\begin{tabular}{|c|c|c|c|}
\hline ASQ-3 Areas & Sally's Scores & Area Cut-Off Scores & Developmental Status \\
\hline \hline Communication & 10 & 33.3 & Concern Supported \\
\hline Goss Motor & 45 & 36.14 & Concern Rejected \\
\hline Fine Motor & 35 & 19.25 & Concern Rejected \\
\hline Problem Solving & 30 & 27.08 & At Risk \\
\hline Personal Social & 20 & 32.01 & Concern Supported \\
\hline
\end{tabular}


performance on a standardized, norm-based test. Choosing from a list of state approved measures, the team decided to use the Battelle Developmental Inventory 2nd edition [33].

\section{Screening Information}

To begin the eligibility evaluation team members reviewed the performance data from the ASQ-3 and the Screening Summary Report. The findings in the Communication and Personal Social areas of the ASQ3 suggest that she does not appear to be functioning as a typical 30 month-old in these areas.

\section{Parent Information}

Sally's parents also provided a description of their daughter's performance and their expectations in their meeting with Rainbow Center staff. This information was summarized in the Screening Summary Report for all areas of the ASQ-3. The screening information gathered from the ASQ-3 as well as additional information provided by her parents was used by the eligibility evaluation team as the basis for beginning the standardized evaluation-which provided the final source of information to determine if Sally is eligible for IDEA services.

\section{Standardized, Normed-Based Test Assessment}

The team used the Battelle Developmental Inventory- $2^{\text {nd }}$ edition (BDI-2) because it meets their state guidelines for the type of assessment/evaluation measure required to determine eligibility. The criteria for determining eligibility for services, in the state where Sally lives, include: a) two standard deviations (SDs) below the mean in one developmental area, or b) one and a half SDs below the mean in two or more developmental domains including: Adaptive, PersonalSocial, Communication, Motor, and Cognitive. Using the information collected in the screening process, the eligibility evaluation team was able to choose an appropriate level to begin the assessment and administer the BDI-2 in a more efficient way. Following completion of the assessment, team members convened and shared their findings that were then used to score Sally's overall performance on the BDI-2 and to write an Eligibility Determination Summary Report.

A comparison of Sally's performance on the BDI-2 in the Personal-Social and Communication domains supported the earlier screening findings. These findings, along with the team's and parental observations, suggest that Sally met the state's criteria for IDEA free public education. The information/data gathered during this eligibility determination serves as the platform from which to begin the third component, programmatic assessment.

\section{Programmatic Assessment}

\section{Scenario}

Based on the results of Sally's assessment, she was found to be eligible for El/ECSE services. Her parents worked closely with an intervention team through Early Childhood SUPPORTS, including an EI and SLP, to evaluate Sally's current level of development and select outcomes for intervention. The programmatic assessment was conducted two weeks after the eligibility evaluation. Sally's family was involved in all stages of the programmatic assessment and in choosing outcomes based on their priorities for Sally. After the programmatic assessment was completed, an IFSP meeting was held that included intervention team members and Sally's parents. Services for Sally and her family started right after the IFSP meeting.

The third component of the proposed framework entails conducting a programmatic assessment using a curriculum-based measure that will yield information relevant for developing goals/objectives or outcomes and intervention content. The intervention team reviewed the screening findings and Screening Summary Report and the eligibility determination findings and the Eligibility Determination Summary Report to form the basis for conducting the programmatic assessment.

The assessment/evaluation measure used by the El/ECSE program for programmatic assessment/ evaluation was the Assessment Evaluation Programming System (AEPS) [4], a curriculum-based measure with associated curricular materials (i.e., AEPS Curriculum), and family involvement materials. Through observation and conversations with the childcare workers, the SLP completed the Social-Communication, Social and Adaptive areas of AEPS Test. Because previous data indicated that Sally scored similarly to her age peers in the Gross Motor, Fine Motor, and Cognitive areas, these three were not assessed further nor were outcomes developed for these areas. In addition to the SLP completing the AEPS Test, the El visited Sally's parents at home to complete the AEPS Family Report with a particular emphasis on the Social-Communication, Social, and Adaptive areas. 
The information from all the previous components of screening, eligibility determination, and programmatic assessment were assembled and an IFSP meeting was held. From the gathered data/information, the team selected two social-communication, one adaptive and two social outcomes for Sally. These outcomes are listed in Table 2.

Table 2: Team Selected Communication, Adaptive, and Social Outcomes for Sally

\begin{tabular}{|c|c|}
\hline \multicolumn{2}{|c|}{ IFSP Outcomes By Area for Sally } \\
\hline \hline 1. & $\begin{array}{c}\text { Social Communication Area } \\
\text { directions without contextual cues. }\end{array}$ \\
\hline 2. & $\begin{array}{c}\text { Sally will use five descriptive words, five action words, and } \\
\text { two pronouns at home and at childcare. }\end{array}$ \\
\hline 3. & $\begin{array}{c}\text { Adaptive Area } \\
\text { spearing or scooping food and bringing it to her mouth with } \\
\text { minimal spillage for all meals at home and at school. }\end{array}$ \\
\hline Social Area \\
\hline 4. & $\begin{array}{c}\text { Sally will initiate and maintain interactions with a familiar } \\
\text { adult for two or more consecutive exchanges (i.e., a } \\
\text { response from Sally and from the adult). }\end{array}$ \\
\hline 5. & $\begin{array}{c}\text { Sally will initiate and maintain interaction with her peers for } \\
\text { two or more consecutive exchanges (i.e., a response from } \\
\text { Sally and from the peer). }\end{array}$ \\
\hline
\end{tabular}

Once the outcomes were selected, the team could plan and execute intervention efforts to be conducted at the childcare center and at home. The team chose to use a naturalistic approach that embeds targeted goals and objectives into daily activities and play. The fourth component of the framework, Progress Monitoring, is designed to evaluate the effectiveness of intervention efforts.

\section{Progress Monitoring}

\section{Scenario}

After intervention outcomes were chosen, the intervention team needed to monitor Sally's progress. For example, her parents could observe her use of targeted words (i.e., IFSP Outcome 2) at least once a week at home while the SLP could collect data on Sally's interactions with adults and peers at the childcare center (i.e., Outcome 4 and 5). The team then reviewed each outcome when they assembled for their monthly meetings. During the first 6 months, the team deemed Sally's progress satisfactory on all outcomes in that the collected information showed consistent improvement on the five targeted outcomes.
This tracking or progress monitoring is essential to determining the effectiveness of intervention efforts. For each of Sally's IFSP outcomes, the team determined a method for gathering information to gauge the effects of intervention. For each outcome, the team made the following decisions: the type of data/information to be collected, the frequency of data/information collection, and who was responsible for ensuring the data/information were collected and transferred into a usable format for the team's review. These aggregated data/information were presented at monthly team meetings enabling the team to determine if Sally was making progress toward acquisition of the five selected outcomes. If progress did not appear adequate, the team was required to review the outcome, the intervention procedures, and determine if some modification was in order. In other words, the data were fundamentally important to the decision making of the team.

\section{SUMMARY}

Sally's example has been offered to provide a concrete description of the four components, and to illustrate the comprehensive and additive features of the proposed framework. Each component serves as a platform for the next set of activities, and therefore ensures the additive dimension of the system. We believe that the virtue of this framework is that it permits the better use of precious resources to assist families and their children who may be at risk or who have disabilities.

\section{A FINAL WORD}

As we noted earlier, our major purpose has been to describe a comprehensive and additive child focused framework to enhance the performance of professionals working with young children and their families. We offer this framework as a means to encourage all professionals associated with El/ECSE to consider how to improve assessment/evaluation services currently being delivered to young children at risk and with disabilities and their families. As we noted earlier, the field of El/ECSE has made significant progress since its inception; however, more work remains. We hope that this paper stimulates on-going discussions on how to create and implement bettercoordinated and integrated systems of service delivery. We believe that these discussions, in turn, will lead to improved efficiency and effectiveness of assessment/ evaluation services that will do much to move the field of El/ECSE forward. 
We end with two additional observations. First, we find that many university training programs continue to prepare professionals using approaches that encourage a disciplinary focus, rather than to prepare personnel to function on teams. We continue to produce entry-level personnel who may know their area of expertise, but who often are poorly prepared to function as a team member. For example, they do not understand or appreciate other's areas of expertise, nor do they have experience in integrating targeted goals across developmental areas. Consequently, these young professionals may perform poorly as team members until they begin to grasp the importance of mutual respect, and the essentials of reciprocal and complementary actions with other team members. Innovations are needed in order to move forward from a disciplinary-focused approach to a multidisciplinary or transdisciplinary teaming approach in the way we prepare future El/ECSE professionals.

Second, we continue to observe that communities are composed of a myriad of services and programs for young children and their families that often do not communicate or share resources even if they have overlapping goals. One often hears communities described as a patchwork of unconnected programs and services. We think a major paradigm shift is in order, a shift that moves medical, educational and social services from separate entities (i.e., silos) to coordinated and complementary programs for young children and their families-both from an inter as well as intra perspective.

Without shifts in university training and service delivery models, even the best of frameworks will likely make only modest differences--at best. Thus, we end this paper as we began it. The field of El/ECSE has come a long way since its inception, BUT much work remains before we can consistently offer programs that use resources wisely to enhance the lives of young children and their families.

\section{REFERENCES}

[1] Guralnick M, Ed. The effectiveness of early intervention. Baltimore: Paul Brookes Publishing 1997.

[2] Bricker D, Macy M, Squires J, Marks K. Developmental screening in your community: an integrated approach for connecting children with services. Baltimore: Paul Brookes Publishing 2013.

[3] Conti G, Heackman J, Pinto R. The effects of two influential early childhood interventions on health and healthy behaviors. Massachusetts: National Bureau of Economic Research 2015; Available from: http://www.nber.org/papers/ w21454.pdf
Bricker D, Ed. Assessment, evaluation, and programming system for infants and children. 2nd ed. Baltimore: Paul Brookes Publishing 2002.

[5] Johnson J, Rahn N, Bricker D. An activity-based approach to early intervention. Baltimore: Paul Brookes Publishing 2015.

[6] Guralnick M, Ed. The developmental systems approach to early intervention. Baltimore: Paul Brookes Publishing 2005.

[7] Greenspan S, Meisels S. Toward a new vision for the developmental assessment of infants and young children. In: Meisels S \& Fenlchel E, editors. New visions for the developmental assessment of infants and young children. Washington, DC: ZERO TO THREE 1996; pp. 11-26.

[8] McLean M, Hemmeter M, Snyder P. Essential elements for assessing infants and preschoolers with special needs. New Jersey: Pearson 2014

[9] Squires J, Bricker D. An activity-based approach to developing young children's social emotional competence. Baltimore: Paul Brookes Publishing 2007.

[10] Frankenburg W, Dodds J, Archer P, et al. Denver II technical training manual. Colorado: Denver Developmental Materials 1996.

[11] Brothers K, Glascoe $F$, Robertshaw N. PEDS: Developmental milestones-an accurate brief tool for surveillance and screening. Clin Pediatr (Phila) 2008; 47(3): 271-279. http://dx.doi.org/10.1177/0009922807309419

[12] Bayley N. Bayley scales of infant and toddler development. 3rd ed. Texas: Harcourt Assessment, Inc; 2006.

[13] Roid G. Stanford-Binet Intelligence Scales. 5th ed. Illinois: Riverside Publishing 2003.

[14] Parks S. Hawaii Early Learning Profile (HELP). California: VORT Corporation 2007.

[15] Spiker D, Hebbeler K, Wagner M, Cameto R, McKenna P. A framework for describing variations in state early intervention systems. Topics Early Child Spec Educ 2000; 20(4): 195207.

http://dx.doi.org/10.1177/027112140002000401

[16] Lynch E, Mercury M, DiCola J, Widley R. The function of a central referral system in interagency identification, eligibility and service delivery: a case study. Topics Early Child Spec Educ 1988; 8(3): 86-97. http://dx.doi.org/10.1177/027112148800800308

[17] Radecki L, Sand-Loud N, O'Connor K, Sharp S, Olson L. Trends in the use of standardized tools for developmental screening in early childhood: 2002-2009. Pediatrics 2011; 128(1): 14-19.

http://dx.doi.org/10.1542/peds.2010-2180

[18] Sand N, Silverstein M, Glascoe F, Gupta V, Tonniges T, O'Connor K. Pediatricians' reported practices regarding developmental screening: Do guidelines work? Do they help? Pediatrics 2005; 116(1): 174-179.

\section{http://dx.doi.org/10.1542/peds.2004-1809}

[19] Danaher J, Shackelford J, Harbin G. Revisiting a comparison of eligibility policies for infant/toddler programs and preschoo special education programs. Topics Early Child Spec Educ 2004; 24(2): 59-67.

http://dx.doi.org/10.1177/02711214040240020101

[20] Ringwalt S. Summary table of states' and territories definitions of/criteria for IDEA Part C eligibility. Early Childhood Technical Assistance Center, March 4, 2015 Available from: http://ectacenter.org/ pdfs/topics/earlyid/ partc_elig_table.pdf.

[21] Macy M, Bagnato S, Macy R, Salaway J. Conventional tests and testing for early intervention eligibility: Is there an evidence base? Infants Young Child 2015; 28(2): 182-204. http://dx.doi.org/10.1097//YC.0000000000000032 
[22] Bagnato S, Neisworth J. Collaboration and teamwork in assessment for early intervention. Child Adolesc Psychiatr Clin N Am 1999; 8(2): 347-363.

[23] American Educational Research Association, American Psychological Association, National Council on Measurement in Education. Standards for educational and psychological testing. Washington, DC: American Educational Research Association 1999.

[24] Brassard $M$, Boehm A. Assessment of emotional development and behavior problems. In: Brassard MR, Boehm AE. Preschool assessment: principles and practices. New York: Guilford Publications, Inc 2007; p. 508-576.

[25] Hebbeler K, Spiker D, Bailey D, et al. Final report of the national early intervention longitudinal study (NEILS); 1997. [updated 2013 Jun 12; cited 2015 Aug 20]: Available from: http://www. sri.com/neils/pdfs/NEILS Final Report_02 07. pdf.

[26] Neisworth J, Bagnato S. The mismeasure of young children: The authentic assessment alternative. Infants Young Child 2004; 17(3): 198-212.

http://dx.doi.org/10.1097/00001163-200407000-00002
[27] Sandall S, Hemmeter M, Smith B, McLean M. DEC recommended practices. A comprehensive guide for practical application in early intervention/early childhood special education. Montana: Division for Early Childhood 2005.

[28] Bagnato S. Authentic assessment for early childhood intervention: best practices. New York: Guilford Press 2007.

[29] Bricker D, Clifford J, Yovanoff $P$, et al. Eligibility determination using a curriculum-based assessment: a further examination. J Early Interv 2008; 31(1): 3-21. http://dx.doi.org/10.1177/1053815108324422

[30] McWilliam R. Routines-based early intervention. Baltimore: Paul Brookes Publishing 2007.

[31] Bagnato S, Neisworth J, Pretti-Frontczak K. LINKing authentic assessment and early childhood intervention: best measures for best practices. 4th ed. Baltimore: Paul Brookes Publishing 2010.

[32] Squires J, Twombly E, Bricker D, Potter L. Ages and Stages Questionnaires user's guide. $3^{\text {rd }}$ ed. Baltimore: Paul Brookes Publishing 2009.

[33] Newborg J. Battelle Developmental Inventory, 2nd ed. Illinois: Riverside Publishing 2005. 